\title{
УЧАСТИЕ АВСТРАЛИИ В ПРОТИВОДЕЙСТВИИ ТЕРРОРИЗМУ В ЮГО-ВОСТОЧНОЙ АЗИИ: МЯГКАЯ СИЛА
}

\author{
Ю. И. МАЛЕВИЧ, К. И. ЯРМОШУК \\ Белорусский государственный университет \\ Минск, Республика Беларусь
}

В данном исследовании рассмотрены особенности участия Австралии в противодействии терроризму в Юго-Восточной Азии (ЮВА) с точки зрения мягкой силы. Мягкая сила в данном исследовании понимается как любые небоевые методы воздействия. Автор аргументирует важность ЮВА для Австралии, оценивает внешнюю и внутреннюю террористическую угрозу для региона и дает характеристику трем инструментам мягкой силы, применяемых Австралией в противодействии угрозе терроризма в субрегионе. Новизна данной работы заключается в том, что данная работа является первым комплексным исследованием особенностей участия Австралии в противодействии терроризму в ЮВА в отечественной историографии, а также результатом междисциплинарного анализа факторов, выделяемых как русскоязычными, так и западными исследователями, преимущественно австралийскими. В результате исследования авторы приходят к выводу, что в целях противодействия террористической угрозе в Юго-Восточной Азии Австралия прибегает к мягкой силе, то есть небоевым методам воздействия, которые представлены следующими инструментами: 1. сотрудничество в рамках АCЕАН, 2. действия против финансирования терроризма, 3. двустороннее и многостороннее сотрудничество Австралии с отдельными странами ЮВА. Результаты работы могут быть использованы для дальнейшей разработки данной темы и в более комплексных исследованиях в сфере международной безопасности.

Ключевые слова: ЮВА; мягкая сила; внутренняя и внешняя угроза; АСЕАН; финансирование терроризма; террористические организации.

Образец цитирования: Малевич Ю. И., Ярмошук К. И. Участие Австралии в противодействии терроризму в Юго-Восточной Азии: мягкая сила// Актуальные проблемы международных отношений и глобального развития : сб. науч. ст. Минск, 2020. Вып. 8. С. 75-87. https://doi.org/10.33581/2311-9470-2020-8-7587

Введение. Согласно концепции реализма, центральной категорией в международных отношениях является категория национально- 
го интереса. Национальный интерес в свою очередь заключается в обеспечении безопасности. Исламское государство - это новый вызов мировому сообществу, новая угроза безопасности, в том числе и в АТР, т.к. ИГ расширяет свое присутствие в регионах мира, включая Северную Африку и ЮВА. Примечательно, что Австралия имеет большие интересы в области безопасности и экономики в ЮВА. Любая обычная военная и нетрадиционные угрозы, включая терроризм, будут проходить через архипелаг к северу Австралии. В этой связи важно рассмотреть австралийские инструменты противодействия террористической угрозе в ЮВА. В результате исследования автор приходит к выводу, что для этих целей Австралия использует мягкую силу. Новизна работы заключается в том, что данное исследование является первым комплексным исследованием в отечественной историографии роли Австралии в противодействии терроризму в ЮВА с характеристикой конкретных инструментов мягкой силы.

Методология исследования. Объект исследования - региональные политические отношения в сфере безопасности. Предмет исследования - роль Австралии в противодействии терроризму в ЮВА. Целью работы является определение и характеристика роли Австралии в противодействии угрозе терроризма в ЮВА. Для достижения данной цели были поставлены следующие задачи:

1. Охарактеризовать современное положение вещей в отношении террористической угрозы в ЮВА.

2. Выявить основные инструменты мягкой силы, применяемые Австралией, и охарактеризовать их.

Для решения этих задач применялись ряд общефилософских (диалектический метод, принцип всесторонности, принцип детерминизма), общенаучных (анализ, синтез) и частнонаучных (историкогенетический, компаративный, историко-ретроспективный) методов.

Историография исследования. Историографию можно разделить на зарубежную и русскоязычную. Принимая во внимание тему исследования, зарубежные ученые в основном являются исследователями из Австралии, их отличительная черта - это глубокая проработанность тематики в преломлении Австралии, подробность и высокая степень детализации описания, наличие актуальных статистических данных. Русскоязычные авторы делают акцент на распространении терроризма в субрегионе и на особенностях участия Австралии в ACEAH. 
Результаты исследования. Современное положение вещей в ЮВА характеризуется наличием внешней и внутренней террористической угрозы. Внешняя представлена ИГИЛ и Аль-Каидой, а внутренняя - региональными террористическими организациями (Джемаа Исламия, Джамаа Аншарут Даула, Группа Абу Сайяф), этническими конфликтами (следует отнести прежде всего Индонезию, Филиппины и Таиланд) и проблемой пиратства как составляющей терроризма (транспортировка боевиков и закупки оружия) ${ }^{1}$.

На протяжении большей части последних 18 лет Австралия придерживается подхода мягкой силы, которая представлена следующими инструментами: 1. сотрудничество в рамках АСЕАН, 2. действия против финансирования терроризма и 3. двусторонним и многосторонним сотрудничеством Австралии с отдельными странами ЮBA [1].

1. Сотрудничество в рамках АСЕАН.

Для стран Юго-Восточной Азии основным инструментом борьбы с международным терроризмом являются механизмы АCЕАН, такие как Региональный форум АСЕАН по безопасности (АРФ), где вопросы, связанные с терроризмом, стали приоритетными после трагических событий 11 сентября 2001 г. Попытки решения данной проблемы распространились и на подписание целого ряда документов, в том числе «Декларации по финансовым мерам противодействия терроризму» 2002 г., «Заявления о контртеррористическом сотрудничестве в области безопасности границ» 2003 г [2].

Австралия - это первый международный актор, с которым АСЕАН установила отношения диалогового партнерства. Канберра поддержала нацеленность Ассоциации на формирование общерегиональной структуры по обсуждению вопросов азиатско-тихоокеанской безопасности. Создание усилиями АСЕАН Регионального форума АСЕАН (АРФ) и Азиатско-тихоокеанского совета по безопасности (АТССБ) происходило при содействии Австралии.

В середине 2000-х гг. сотрудничество между АСЕАН и Австралией активизировалось. Предвидя усиление Китая в ЮВА, Ассоциация диверсифицировала отношения с внешними партнерами. На фоне бума заключения азиатско-тихоокеанскими экономиками двусторон-

\footnotetext{
${ }^{1} 2017$ Foreign Policy White Paper [Electronic resource] // Australian Government. 2017. URL: https://www.fpwhitepaper.gov.au/foreign-policy-white-paper. (accessed: 28.02.2020).
} 
них и многосторонних соглашений о свободной торговле, АСЕАН решила разработать их потенциал в отношениях с Австралией. Одновременно стороны расширили сотрудничество в противодействии нетрадиционным угрозам безопасности. Австралия предоставила помощь странам ЮВА, пострадавшим от землетрясения и цунами в декабре 2004 г. Активизировались совместные мероприятия по борьбе с международным терроризмом. Кульминацией асеановскоавстралийского сотрудничества можно обоснованно считать середину 2000-х - вторую половину 2010-х гг. В 2005 г. Австралия подписала Договор АСЕАН о дружбе и сотрудничестве и вошла в число стран участниц Восточноазиатского саммита (ВАС), а 2010 г. - Совещания министров обороны (CMO) АСЕАН+8. В 2014 г. АСЕАН и Австралия заключили соглашение о стратегическом партнерстве, а год спустя приняли решение проводить саммиты на уровне глав государств и правительств каждые два года [3]. В 2018 году 33-й саммит АСЕАН проходил в Австралии, который включал в себя Конференцию по борьбе с терроризмом. Конференция была основана на Совместной декларации АСЕАН-Австралия 2016 года о сотрудничестве в борьбе с международным терроризмом и направлена на «укрепление региональных связей и сотрудничества в борьбе с терроризмом и насильственным экстремизмом», а также на субрегиональном совещании по борьбе с иностранными террористами и трансграничным терроризмом (The Sub-Regional Meeting on Foreign Terrorist Fighters and Cross Border Terrorism). Основное внимание на саммитах было уделено значению АСЕАН как силы для «стабильности», «процветания» и «безопасности» в регионе, а также необходимости выработки скоординированных мер реагирования на угрозы, которые возвращающиеся иностранные боевики-террористы представляют для региона [4]. Внимание на саммите было также приковано к социальным сетям и зашифрованным сообщениям. По всей Юго-Восточной Азии свобода в киберпространстве находится в упадке, поскольку правительства вводят меры по ограничению доступа к Интернету и свободы слова. Часто утверждается, что такие меры направлены на повышение безопасности. Требование правительств, таких как Великобритания и Австралия, Франция и Германия, иметь возможность доступа к зашифрованным сообеениям, а также необходимость «регулировать» Интернет посредством предотвращения распространения радикаль- 
ных материалов, являются основными темами в эволюции антитеррористической политики [5].

Согласно Меморандуму о взаимопонимании, принятому по итогам саммита, Австралия будет оказывать техническую поддержку своим партнерам по АСЕАН в области борьбы с терроризмом и пресечения финансирования терроризма. Австралия также будет содействовать региональному диалогу по законодательству о борьбе с терроризмом, а также по инициативам по созданию потенциала для выявления и пресечения террористической деятельности [5].

Региональный форум АСЕАН по безопасности (АРФ) на сегодняшний день остается, пожалуй, единственной организацией в АТР, непосредственно занимающейся широким спектром проблем безопасности в регионе. АРФ осуществляется по двум направлениям. Первое направление связано с взаимодействием по правительственной линии и мероприятиями на официальном уровне. Bторое направление обеспечивает сотрудничество и обмен мнениями на уровне экспертов стран - членов АРФ [6].

Австралия уделяет первостепенное внимание расширению своего участия в Совещании министров обороны стран АCЕАН (CMO ACEAH). Совещание фокусируется на практических мерах, направленных на улучшение понимания и содействие практическому сотрудничеству в решении проблем безопасности, включая борьбу с терроризмом, безопасность на море, гуманитарную помощь и поддержание мира. Австралия помогает наращивать коллективный потенциал региона в борьбе с терроризмом в рабочей группе экспертов по борьбе с терроризмом СМО АСЕАН [7].

Также примечательна поддержка Австралией создания Рабочей группы по финансированию борьбы с терроризмом в Юго-Восточной Азии, целью которой является борьба и блокирование финансирования терроризма. Председателями рабочей группы являются Австралия и Филиппины. Группа вышла из Азиатско-тихоокеанского саммита по борьбе с терроризмом, который состоялся в Сиднее в 2015 г., а год спустя - на совещании в Бали. В 2017 г. AUSTRAC (Австралийский центр отчетов и анализа транзакций), банк Negara Malaysia и индонезийский Pusat Pelaporan dan Analisis Transaksi Keuangan выступили спонсорами 3-го Саммита по борьбе с финансированием терроризма (Counter-Terrorism Financing Summit), который состоялся в 
Куала-Лумпуре. Четвертый саммит состоялся в Бангкоке в ноябре 2018 г. [4].

2. Действия Австралии против финансирования терроризма.

В последние годы террористами в регионе стал использоваться такой канал мобилизации финансов как сбор средств через социальные сети и привлечение денежных ресурсов частных лиц из числа Интернет сообщества. Незадолго до теракта в Джакарте в январе 2016 г. гражданин Австралии, сочувствующий джихадистам, переслал исламистским группировкам в Индонезии 500 тыс. долл. [8]. Реагируя на призывы террористов, люди, симпатизирующие им, переводят на их счета средства онлайн, которые затем собираются и переправляются по официальным каналам через банки или электронные переводы. Подобного рода риски финансирования террористов оцениваются по высшей шкале для Индонезии и Малайзии. Имеются доказательства того, что индонезийские джихадисты получили от террористического подполья в Австралии 375 тыс. долл. США [8]. Самым последним арестом в области финансирования в Австралии был арест федерального государственного служащего Линды Мери в январе 2018 г. Ведется расследование и предполагается, что Мери передала более 30 000 долларов США Исламскому государству. Арест Л. Мери произошел в результате операции “Operation Peqin”, которая ранее привела к аресту 16-летней школьницы из Сиднея в 2016 г. по обвинению в финансировании: \$ 17850 было переведено австралийскому бойцу ИГ посредством нескольких переводов через Western Union в период с 2015 по 2016 год [9]. На фоне того, что проблема финансирования террористов в Австралии является очень актуальной, Австралия предпринимает активные действия для борьбы с финансированием терроризма.

Правительство Австралии предоставляет большое финансирование для этой цели, уделяя основное внимание Юго-Восточной Азии после падения ИГ на Ближнем Востоке. В сентябре 2017 г. было выделено 4,6 млн. долл. США на три года для инициативы под руководством AUSTRAC (Австралийский центр отчетов и анализа транзакций) по блокированию финансирования для групп, ориентированных на ИГ в регионе. В декабре 2017 г. было объявлено о выделении более 5,5 млн. долл. США для создания новой международной программы финансовой разведки и регулирования. Это финансирование предназначено для расширения международного присутствия 
AUSTRAC за пределами его нынешнего нахождения в Индонезии и на Филиппинах путем размещения сотрудников AUSTRAC в Малайзии, Сингапуре, Китае, на Ближнем Востоке, в Лондоне и Вашингтоне [9]. В 2015 г. австралийское подразделение финансовой разведки AUSTRAC и его индонезийский коллега PPATK (Индонезийский центр отчетов и анализа транзакций) основали Азиатскотихоокеанский саммит по борьбе с терроризмом (The Asia-Pacific Counter-Terrorism Financing Summit), который проводится каждый год. Рабочие группы, созданные в рамках саммита, проделали важную работу, прежде всего дали первую в мире региональную оценку риска в отношении финансирования терроризма. Эта оценка была важна, потому что она предоставила основанные на фактических данных оценки того, где наибольший риск финансирования терроризма лежит в каждой стране-участнице. Он также подчеркнул тот факт, что риски финансирования терроризма не одинаковы во всех странах; скорее они варьируются от страны к стране в зависимости от ряда факторов, таких как география и характер экономической и финансовой системы страны [9].

Также Австралия признает, что требуется более широкий обмен информацией и сотрудничество между правительством и частным сектором. В развитых западных странах, таких как Австралия, большая часть финансирования терроризма осуществляется с использованием услуг или платформ, предоставляемых частным сектором, особенно сектором банковских и финансовых услуг. Тем не менее, частный сектор нуждается в информации от правительства об актуальных тенденциях в терроризме, чтобы знать, что искать ${ }^{2}$. Опять же, AUSTRAC лидирует в укреплении государственно-частного партнерства через свою инициативу Fintel Alliance. Хотя это партнерство имеет широкую направленность на борьбу с финансовыми преступлениями, оно должно способствовать развитию более тесных отношений и сотрудничества между государственными органами и компаниями частного сектора. Fintel Alliance также предоставляет механизм для более быстрого расследования разворачивающихся террористических заговоров и атак. Например, эта инициатива использовалась для быстрого расследования в конечном счете неудачного заго-

2 Cyber security strategy 2016 [Electronic resource] // Australian Department of Home Affairs. 2016. URL: https://www.pmc.gov.au/sites/default/files/publications/australias-cyber-securitystrategy.pdf. (accessed: 20.04.2020). 
вора ИГ по размещению взрывчатки на авиалайнере в аэропорту Сиднея [9]. Однако властям Австралии необходимо быть бдительными в отношении более широкого использования нетрадиционных или новых методов, таких как криптовалюты и социальные сети. О изменяющихся тенденциях необходимо будет сообщать частным компаниям, а правительству необходимо развивать более тесное сотрудничество с нетрадиционными партнерами, такими как биржи цифровых валют и владельцы социальных сетей [9].

3. Двустороннее и многостороннее сотрудничество Австралии с отдельными странами ЮВА.

После взрывов на Бали в 2002 г. Австралия и Индонезия укрепили свои отношения в борьбе с терроризмом и насильственным экстремизмом. Австралийская федеральная полиция (АФП) и Служба дипломатической безопасности и антитеррористической помощи Государственного департамента США (US State Department's Diplomatic Security Service and Anti-Terrorism Assistance Program) сыграли важную роль в поддержке и обучении «Денсус 88» (Densus 88) (специализированное подразделение по борьбе с терроризмом в рамках программы МВД Индонезии). Важно, что «Денсус 88» может действовать как группа тактического реагирования и, поскольку в ней также есть технические эксперты, такие как специалисты по взрывчатым веществам и криминалистической экспертизе, а также люди, обученные цифровой криминалистике, она может применять более комплексный подход к реагированию на террористические угрозы и атаки. В период с 2012 по 2018 год правоохранительные органы Индонезии предотвратили более 500 террористических заговоров [4].

Еще одним примером является поддержка Австралией создания специализированного центра по борьбе с терроризмом - Джакартского центра сотрудничества между правоохранительными органами (ДЦСПО) (the Jakarta Centre for Law Enforcement Cooperation) - который начал свою работу при поддержке Австралии в 2004 г. Он совместно управляется индонезийской национальной полицией и Австралийской федеральной полицией. ДЦСПО проводит тренинги для сотрудников правоохранительных органов по таким вопросам, как противодействие насильственному экстремизму, расследование финансирования терроризма и использование социальных сетей в борь- 
бе с терроризмом. Он организовал обучение примерно 17000 индонезийских и региональных сотрудников правоохранительных органов ${ }^{3}$.

Когда в 2017 г. произошла битва за Марави (вооружённый конфликт в городе Марави между филиппинским правительством и исламистскими вооружёнными группировками Мауте (подразделение ИГИЛ) и «Абу Сайяф» в мае 2017 г.), Австралия предоставила техническую экспертизу армии Филиппин в рамках операции "Augury Philippines". Австралия смогла обеспечить такую подготовку, потому что австралийский спецназ боролся с подобным типом террористов в Ираке и Афганистане (Австралия направила около 80 военных инструкторов, имеющих навыки ведения городской войны, на Филиппины). Австралия также предоставила два самолета наблюдения «Орион» АР-3С для обеспечения наблюдения и разведки, чтобы помочь наземным командирам Филиппин. После битвы отношения между двумя странами расширились. Мариза Пэйн в качестве министра обороны Австралии заявила, что «практическая подготовка, которую проводит Австралийские силы обороны (АСО), обеспечит, чтобы силы обороны Филиппин могли лучше противостоять жестокой тактике, применяемой террористами». После осады Марави в октябре 2017 г. вклад Австралии в рамках операции “Augury Philippines" позволил провести тренинг по борьбе с терроризмом для более чем 10000 военнослужащих Вооруженных сил Филиппин. Это учебное сотрудничество включало основные наземные мероприятия, ориентированные на городские боевые действия и навыки совместной координации; воздушная подготовка, направленная на улучшение координации воздушного движения в городской среде; и морские учебные мероприятия ${ }^{4}$.

Также стоит отметить, что кроме Индонезии и Филиппин, Австралия имеет давнюю программу сотрудничества в области обороны с Таиландом, Вьетнамом, Сингапуром и Малайзией в области борьбы с терроризмом, противодействия самодельным взрывным устрой-

\footnotetext{
${ }^{3}$ Australia's Counter-Terrorism Strategy: Strengthening Our Resilience 2015// Australian National Security official website [Electronic resource]. 2015. URL: https://www.nationalsecrity.gov.au/ Media-and-publications/Publications/Documents/Australias-Counter-Terrorism-Strategy-2015.pdf. (accessed: 25.04.2020).

4 Operation Augury-Philippines transitions to Enhanced Defence Cooperation Program: Joint Statement// Australian Defence Department [Electronic resource]. 2019. URL: https://www.minister.defence.gov.au/minister/lreynolds/media-releases/operation-auguryphilippines-transitions-enhanced-defence (accessed: 10.03.2020).
} 
ствам, поддержания мира, безопасности на море, логистики, развития потенциала, безопасности полетов и обучению английскому языку ${ }^{5}$.

На многостороннем треке стоит отметить Пятистороннее оборонное соглашение (FPDA - The Five Power Defence Arrangements) c Малайзией, Сингапуром, Новой Зеландией и Великобританией, которое является самым давним механизмом региональной безопасности для Австралии. Это соглашение является единственным многосторонним соглашением по безопасности, ориентированным на практическое сотрудничество такого рода в регионе Юго-Восточной Азии. Вклад Австралии заключается в организации сложных комплексных учений высокого уровня.

Выводы. Таким образом, современное положение вещей в ЮВА характеризуется наличием внешней и внутренней террористической угрозы. Внешняя представлена ИГИЛ и Аль-Каидой, а внутренняя региональными террористическими организациями, этническими конфликтами и проблемой пиратства.

Мягкая сила Австралии в ЮВА представлена следующими инструментами:

1. Сотрудничество в рамках АСЕАН (участие Австралии в Региональном форуме АСЕАН (АРФ), Азиатско-тихоокеанском совете по безопасности (АТССБ), Восточноазиатском саммите (ВАС), Совещании министров обороны ACEAН (CMO ACEAН), Рабочей группе по финансированию борьбы с терроризмом в Юго-Восточной Азии, Саммите по борьбе с финансированием терроризма, принятие совместной декларации АСЕАН - Австралия 2016 года о сотрудничестве в борьбе с международным терроризмом),

2. Действия против финансирования терроризма (образованный совместно с Индонезией Азиатско-тихоокеанский саммит по борьбе с терроризмом, австралийская инициатива Fintel Alliance по укреплению государственно-частного партнерства),

3. Двусторонним и многосторонним сотрудничеством Австралии с отдельными странами ЮВА (двустороннее сотрудничество в сфере обороны и борьбы с терроризмом с Индонезией, Таиландом, Вьетнамом, Филиппинами, Сингапуром и Малайзией и на многосто-

\footnotetext{
5 Defence White Paper 2016// Australian Defence Department [Electronic resource]. 2016. URL: http://www.defence.gov.au/WhitePaper/Docs/2016-Defence-White-Paper.pdf 10.04.2020).

(accessed:
} 
роннем треке Пятистороннее оборонное соглашение с Малайзией, Сингапуром, Новой Зеландией и Великобританией).

\section{Библиографические ссылки}

1. Jones, S. A Persistent Threat: the evolution of al Qa'ida and other salafi jihadists [Electronic resource] / S. Jones // The Australian Strategic Policy Institute. URL: access:https://www.rand.org/content/dam/rand/pubs/research_reports/RR600/RR637/RAND_RR637. pdf. (accessed: 22.05.2020).

2. Морозов, Н. Террористическая угроза распространения «Исламского государства» в Азиатско-Тихоокеанском регионе /Н. Морозов // Азиатско-Тихоокеанский регион: экономика, политика, право. 2015. № 4. С. 22-34.

3. Канаев, Е. Сотрудничество АСЕАН с Австралией и безопасность на морях АТР/Е. Канаев // Юго-Восточная Азия: актуальные проблемы развития. 2017. № 38. С. 76-88.

4. Kfir, I. 18 years and counting Australian counterterrorism, threats and responses/ I. Kfir // The Australian Strategic Policy Institute [Electronic resource]. 2019. URL: https://s3-ap-southeast2.amazonaws.com/ad-aspi/2019-

04/18\%20Years\%20and\%20counting.pdf?5J2Se2RxM9CZa6QD5300yij_wP4f.ANm. (accessed: 02.04.2020).

5. Kfir, I. Australia and ASEAN's evolving counter-terrorism regime / I. Kfir // The Australian Strategic Policy Institute [Electronic resource]. 2018. URL: https://www.aspi.org.au/opinion/australia-and-aseans-evolving-counter-terrorism-regime (accessed: 02.04.2020).

6. Асатрян, Л. Режимы безопасности в Азиатско-Тихоокеанском регионе/Л. Асатрян // Регион и Мир.2019. № 6. С. 38-43.

7. Васильев, Л. Проблемы безопасности в Юго-Восточной Азии. Борьба с терроризмом, сепаратизмом и экстремизмом/Л. Васильев // Северо-Восточная Азия: региональные измерения безопасности и Российско-Китайское сотрудничество: сб. ст. Федеральн. Гос. бюджетного учрежд. науки/ Институт Дальнего Востока РАН. Москва, 2014. С. 188-221.

8. Рогожина, Н. Финансирование терроризма в странах Юго-Восточной Азии/Н. Рогожина // Юго-Восточная Азия: актуальные проблемы развития. 2017. № 35. С. 70-77.

9. Kfir, I., Grice, G. Counterterrorism yearbook 2019/ I. Kfir, G. Grice // RAND - National Defense Reserach Institute [Electronic resource].2014. URL: https://s3-ap-southeast2.amazonaws.com/ad-aspi/2019-

03/ASPI\%20Counterterrorism\%20YB2019_acc_1.pdf?VWvpiCRC_om4gXFvmBHvSn0NIDNOr MvM (accessed: 25.04.2020).

Дата поступления статьи: 30.09.2020.

Авторы: Малевич Юлианна Игоревна - доктор политических наук, профессор, профессор кафедры международных отношений БГУ; e-mail: myjil1352@gmail.com. Ярмошук Карина Игоревна - аспирант кафедры международных отношений БГУ; e-mail: karinayarmoshuk@gmail.com 


\title{
AUSTRALIA'S COUNTER TERRORISM INVOLVEMENT IN SOUTHEAST ASIA: SOFT POWER \\ Y. I. MALEVICH, K. I. YARMOSHUK
}

Belarusian State University

Minsk, Republic of Belarus

\begin{abstract}
Taking into account that Australia at the present stage plays the role of an "active citizen" in the world, is in a military-political alliance with the United States - the leader of the anti-terrorist coalition, is a leader in ensuring security in the South Pacific, and also that one of the priorities of Australia's foreign policy is security, it is important to consider the instruments that Australia uses in the fight against terrorism. Australia has great interests in security and economics in Southeast Asia. Any conventional military and non-traditional threats, including terrorism, will pass through the archipelago to the north of Australia. In this regard, it is important to assess Australia's ability to counter the terrorist threat in Southeast Asia. This study looks into the characteristics of Australia's involvement in countering terrorism in Southeast Asia in terms of soft power. The purpose of the study is to identify the role and to characterize Australia's soft power tools in countering terrorism in Southeast Asia. The author describes the importance of Southeast Asia for Australia, assesses the external and internal terrorist threats to the region and gives a description of the three soft power tools used by Australia in countering the threat of terrorism in the region. The novelty of this work is in the fact that the study is the result of an analysis of factors highlighted by both Russian-speaking and Western researchers, mainly Australians. The results of the work can be used for the further development of this topic and in more comprehensive studies in the field of international security.
\end{abstract}

Keywords: Southeast Asia; soft power; internal and external threats; ASEAN; terrorist financing; terrorist organizations.

For citation: Malevich, Y. I., Yarmoshuk, K. I. (2020). Australia's counter terrorism involvement in Southeast Asia: soft power In: Actual Problems of International Relations and Global Development: collection of scientific papers. Minsk, Vol. 8, p. 7587. https://doi.org/10.33581/2311-9470-2020-8-75-87

\section{References}

1. Jones, S. A. (2019). Persistent Threat: the evolution of al Qa'ida and other salafi jihadists. URL: https://www.rand.org/content/dam/rand/pubs/research_reports/RR600/RR637/RAND_RR637.pdf. (accessed: 22.05.2020). 
2. Morozov, N. (2015). Terroristicheskaja ugroza rasprostranenija «Islamskogo gosudarstva» v Aziatsko-Tihookeanskom regione. [Terrorist threat of the proliferation of the "Islamic State" in the Asia-Pacific region] In: Asia-Pacific region: economics, politics, law, 4. p. 22-34. (In Russ).

3. Kanaev, E. (2017). Sotrudnichestvo ASEAN s Avstraliej i bezopasnost' na morjah ATR [ASEAN cooperation with Australia and security at the seas of the Asia-Pacific region]. In: Southeast Asia: topical development problems, 38. p. 76-88. (In Russ).

4. Kfir, I. (2019). 18 years and counting Australian counterterrorism, threats and responses. URL: https://s3-ap-southeast-2.amazonaws.com/ad-aspi/2019-

04/18\%20Years\%20and\%20counting.pdf?5J2Se2RxM9CZa6QD5300yij_wP4f.ANm. (accessed: 02.04.2020).

5. Kfir, I. (2018). Australia and ASEAN's evolving counter-terrorism regime. URL: https://www.aspi.org.au/opinion/australia-and-aseans-evolving-counter-terrorism-regime (accessed: 02.04.2020).

6. Asatrjan, L. (2019). Rezhimy bezopasnosti v Aziatsko-Tihookeanskom regione [Security regimes in the Asia-Pacific region]. In: Region and World, 6. p. 38-43. (In Russ).

7. Vasil'ev, L. (2014). Problemy bezopasnosti v Jugo-Vostochnoj Azii. Bor'ba s terrorizmom, separatizmom i jekstremizmom [Security problems in Southeast Asia. The fight against terrorism, separatism and extremism]. In: Northeast Asia: Regional Security Dimensions and Russia-China Cooperation: collection of scientific papers. Institute of the Far East of the Russian Academy of Sciences. Moskow, p. 188-221. (In Russ).

8. Rogozhina, N. (2017). Finansirovanie terrorizma v stranah Jugo-Vostochnoj Azii [Financing of terrorism in the countries of South-East Asia]. In: Southeast Asia: topical development problems, 35. 70-77. (In Russ)

9. Kfir, I., Grice, (2014). G. Counterterrorism yearbook 2019. URL: https://s3-ap-southeast2.amazonaws.com/ad-aspi/2019-

03/ASPI\%20Counterterrorism\%20YB2019_acc_1.pdf?VWvpiCRC_om4gXFvmBHvSn0NIDNOr

MvM (accessed: 25.04.2020).

Received: 30.09 .2020 .

About authors: Malevich Yulianna Igorevna - Doctor of Political Sciences, Professor, Professor of the Department of International Relations of the Belarusian State University; e-mail: myjill352@gmail.com. Yarmoshuk Karina Igorevna - postgraduate student of the Department of International Relations, BSU; e-mail: karinayarmoshuk@gmail.com 